\title{
INTRA-ABDOMINAL HYPERTENSION IN THE ICU - A PROSPECTIVE EPIDEMIOLOGICAL STUDY
}

\author{
GEORGI M. ARABADZHIEV ${ }^{1}$, VALENTINA G. TZANEVA ${ }^{2}$, \\ KATYA G. PEEVA ${ }^{3}$
}

\author{
${ }^{1}$ Department of Pediatric Surgery, Anesthesia and Emergency Medicine, Trakia \\ University, Medical Faculty, Stara Zagora, Bulgaria \\ ${ }^{2}$ Department of Infection Diseases and Epidemiology, Trakia University, Medical \\ Faculty, Stara Zagora, Bulgaria \\ ${ }^{3}$ Department of Social Medicine and Health Management, Trakia University, \\ Medical Faculty, Stara Zagora, Bulgaria
}

\begin{abstract}
The aim of this prospective study is to examine the frequency and the severity of intra-abdominal hypertension in a mixed ICU of the University hospital.

Methods. A closed system for intravesical intermittent measurement of IAP was constructed.

Results. The frequency and the severity of IAH were examined in the period from June 2009 to December 2012 in 240 ICU patients divided into 3 groups (patients submitted to elective surgery, emergency surgery, and medical patients) in the University Hospital. In the elective surgery group there was $12.5 \%$ IAH, while in the emergency group IAH was $43.75 \%$, and in the medical patients it was $42.5 \%$. There was no statistical significant difference in the frequency of IAH among the mixed population of patients we examined and those studied by other authors with the same type of population.

Conclusions. The standardized measurement of intra-abdominal pressure is fundamental for defining intra-abdominal hypertension and abdominal compartment syndrome. The measurement of intra-abdominal pressure should be a part of the basic monitoring of patients at risk of intra-abdominal hypertension. Our point of view is that before there are indications for a surgical decompression, less invasive treatment options should be optimized.
\end{abstract}

Keywords: intra-abdominal hypertension, abdominal compartment syndrome, intra-abdominal pressure.

Theinterestand clinical studies of the intra-abdominal hypertension (IAH) and abdominal compartment syndrome (ACS), as a main factor causing significant morbidity and mortality in critically ill patients in the intensive care units, has increased exponentially around the end of decade. Kimbal et al. (2006) in a survey among 4538 members of the Society of Critical Care Medicine established that $47 \%$ of the intensivists involved in the treatment of surgical patients experienced the problem with ACS, whereas $25 \%$ of the therapeutic and pediatric intensivists have never seen a patient with abdominal compartment syndrome

Manuscript received: 02.02.2015

Accepted: 06.03.2015

Address for correspondence: garabadzhiev@yahoo.com
[1]. In a similar study that took place in 207 hospitals in the UK, Ravishankar and Hunter (2005) established that $1.5 \%$ of ICU doctors never heard of IAH/ACS, and $75.9 \%$ measured intra-abdominal hypertension $-93.2 \%$ of them when developing suspicion of ACS, 3.8\% in every case of emergency laparotomy and $2.9 \%$ in emergency laparotomies and massive infusion therapy [2]. Nagappan et al. (2005) interviewed 40 Australian ICU registrars and found that $92 \%$ of them measured regularly intra-abdominal pressure and believed that the abdominal compartment syndrome should be treated with decompressive laparotomy; 33\% assume wrongly that the ACS is pressure above $30 \mathrm{mmHg}$, not having in mind organ dysfunction, and $22 \%$ are not 
sure what value of IAP requires treatment [3]. Costa et al. (2011) conducted a survey among Portuguese general surgeons revealing that all of them had heard of measuring intra-abdominal pressure, $89 \%$ monitored it regularly, but only $22 \%$ knew the correct value of IAP, which determines the presence of intra-abdominal hypertension, $36.3 \%$ believed that decompressive laparotomy should be performed at a pressure above $20 \mathrm{mmHg}$ combined with the onset of organ dysfunction, and $48.4 \%$ of these surgeons had already performed decompressive laparotomy [4]. In a study among German anesthesiologists and surgeons Kaussen et al. (2012) concluded that $26 \%$ do not measure IAP, $41 \%$ measured it only in cases of high risk of developing abdominal compartment syndrome, and $30 \%$ measured it routinely, while $94 \%$ of all respondents used the intravesical method. The same authors in a study among German pediatric intensivists found that $20 \%$ of respondents performed routine measurement of IAP and $17 \%$ only measured IAP in case of organ dysfunction and failure [5].

In response to the great interest and the need to standardize and unify all definitions, classifications and protocols for the monitoring and management of intraabdominal hypertension and the abdominal compartment syndrome the World Society of the Abdominal Compartment Syndrome (WASCS) was created in Noosa, Australia, in 2004.

\section{Aim}

One of the main purposes corresponding to the good medical practice is the optimization of organ function and identification of clinical events that have a negative effect on the outcome of treatment. The intra-abdominal hypertension has become one of the significant prognostic indicators for a critically ill patient's outcome, not only surgical but also medical. Intensive monitoring and diagnosis of the causes of IAH has become vital.

Considering the complications that are associated with elevated IAP we aimed to investigate the frequency and severity of IAH in our patients in mixed ICU.

\section{Materials and methods}

The technique for intermittent transurethral intravesical measurement of intra-abdominal pressure in a closed system is shown at Fig. 1. The Foley catheter is associated with Y-connector (PB1204, Coloplast AS, Denmark); one of the arms is connected to the drain pipe of the collector for urine and the other by conical connector (B. Braun REF: 4896629, alternatively B. Braun REF: 4438450); with extension tube for measuring low pressure (B. Braun REF: 5205263) and an installation consisting of two consequently fitted three-way stopcock, a druckdome (B. Braun REF: 5204100) for reusable transducer (50 $\mu \mathrm{V} / \mathrm{V} / \mathrm{cmHg}$, Sensonor AS Horten, Norway) and a third three-way stopcock used to reset the transducer. To the first

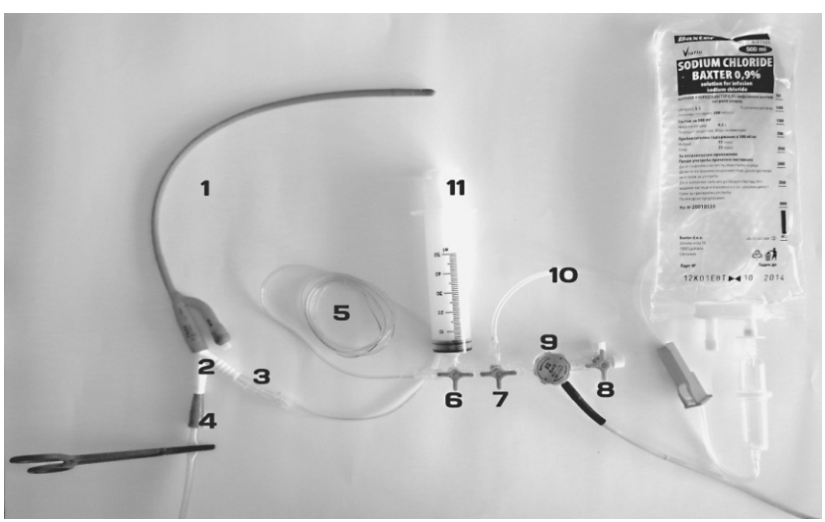

Figure 1. 1. Foley catheter; 2. Y-connector; 3. Conical connector with luerlock liaison; 4. Draining pipe of the collector for urine; 5. Extension line; 6, 7, 8. Three-way stopcocks; 9. Camera with transducer for pressure; 10. Infusion set with bag of $500 \mathrm{ml} 0.9 \%$ $\mathrm{NaCl} ; 11.50 \mathrm{ml}$ syringe.

three-way stopcock with a luerlock connection is inserted a syringe $50 \mathrm{ml}$, the second is connected to an infusion set with a bag of $500 \mathrm{ml}$ of normal saline $(0.9 \% \mathrm{NaCl})$. Before connecting the described installation to the Foley catheter, the latter should be washed out to eliminate the bubbles.

Methods for intermittent intravesical measuring of $I A P$. To measure intravesical pressure clamp the drain pipe immediately under the Y-connector, close the first threeway stopcock to the patient and open the second three-way stopcock connected to the infusion bag, which is closed to the camera transducer. Aspirate $50 \mathrm{ml}$ solution, close the second three-way stopcock to the infusion system, open the first tap to the urethral catheter and then introduce $25 \mathrm{ml}$ solution into the bladder. Close the first three-way stopcock to the patient and open the second connected to the chamber, and keep opened the third faucet after the camera. Using a few milliliters solution we once again irrigate the transducer dome in case of any air bubbles. Close the second three-way stopcock to the dome and through the opened third threeway stopcock reset the transducer on mid axillary line level by cresta iliaca, then close the third three-way stopcock. Open the second and the first three-way stopcock to the urethral catheter and record the results after 2 minute pause in order to avoid false high results, which may be caused by possible detrusor contractions from the introduction of fluid volume. Observed variations in respiratory curve, and an oscillation test is conducted before recording the results. The measuring is conducted when placing the patient in a fully supine position and at the end of expirium. The used solution is at room temperature. After monitoring an average value of the measured pressure, the first three-way stopcock to the patient is closed and the draining tube is declamped. From the obtained hour diuresis draw out the initially imported $25 \mathrm{ml}$ solution.

This indirect method of IAP monitoring was validated in a study on patients undergoing laparoscopic cholecystectomy $(n=30)$ as intravesical measured values 
were compared with those from direct IAP measured by carbon dioxide insufflator. According to WSACS two techniques of intra-abdominal pressure measurement may be considered equivalent if the analysis of Blant Altman has bias $<1 \mathrm{mmHg}$, and accuracy (defined as the standard deviation of bias) to $2 \mathrm{mmHg}$, or limits of agreement (LA) -4 to $+4 \mathrm{mmHg}$. Based on the analysis of the study of this method, we may conclude that the results obtained by indirect IAP measurement with this technique were not statistically different from those obtained by direct method and should be considered as reliable and reproducible.

Statistical methods: Descriptive statistics for quantitative and qualitative variables; Nonparametric analysis for the evaluation of hypotheses for data with nonGaussian distribution and Kruskal-Wallis test; D'AgostinoPearson test of normality of distribution. For hypotheses evaluation by comparing the data from each of the groups the Dunnett multiple comparative test was administered. Bland Altman plot was used to evaluate the hypotheses in a comparison of the two methods, evaluating the same indicator of mismatch. Level of significance used was $\mathrm{P}<0.05$.

\section{Results}

Patients were divided into 3 groups - 2 surgical (after routine and emergency interventions) and one medical (Tables I, II, III). For the period June 2009 - December 2012, 80 patients following elective surgery interventions entering the ICU for more than 48 hours were randomly chosen to form the elective surgery subgroup. We included all cases of emergency surgical and therapeutic patients who were admitted to the unit until 2 p.m., on workdays only and with defined diagnosis until the formation of the other two groups. Patients who died during follow-up (72 hours) and those occasionally transferred to another unit (usually due to lack of available beds in the ICU) dropped out of the study due to incomplete set of measurements; those in which for some reason not all measurements were performed were also excluded, and other patients were included in their place. Exclusion criteria: age under 18 years, contraindications for intravesical measurement of IAP.

For the purpose of the screening of incidences of intra-abdominal hypertension the intra-abdominal pressure was measured by the intravesical technique described above, after admission of the patient to the intensive care unit at 2 p.m., then afterwards at a specific 6-hour interval -
6 hours later at 8 p.m., after 12 hours at 8 a.m., and after 6 hours at 2 p.m.. On the second and third day these intervals were kept the same. The complete set of measurements for each patient was 10. During each measurement an average value of IAP was recorded, and then the average values for the day was calculated, as well as the average values for the 72 hour period.

The obtained results for the frequency and severity of intra-abdominal hypertension in the study population of patients in the intensive care unit are presented in Table IV and Figure 2.

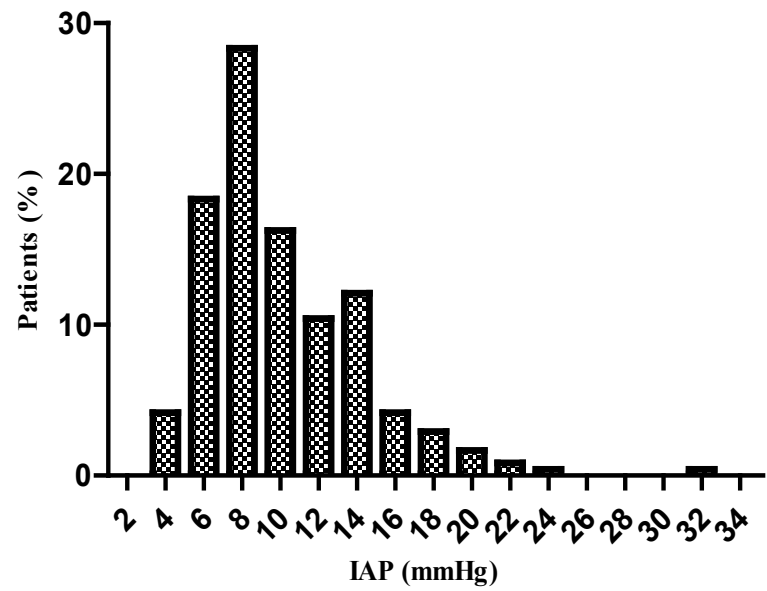

Figure 2. Distribution of IAH in the whole population for 72 hours.

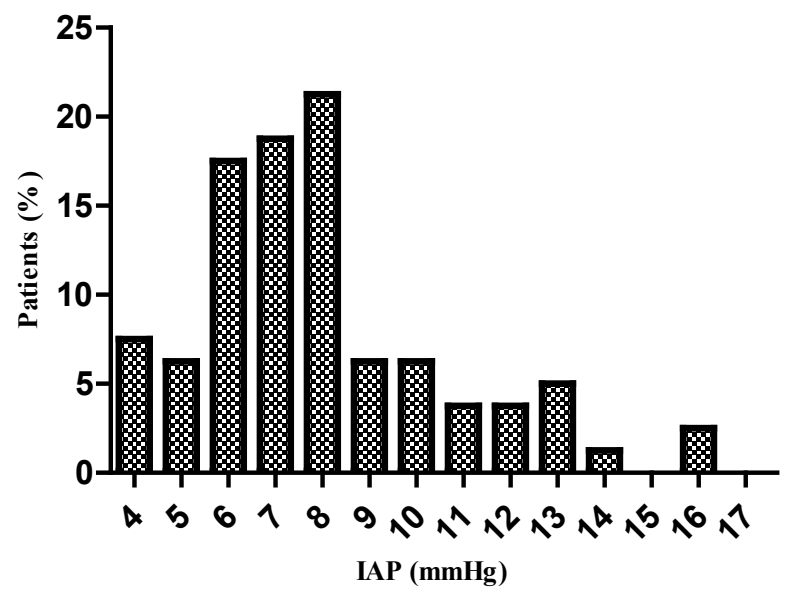

Figure 3. Incidence of IAH in Group A - planned postoperative patients.

Table I. Demographic data.

\begin{tabular}{llllll}
\hline & All patients & Group A & Group B & Group C & Sig. P \\
\hline Number $(\mathrm{n})$ & $\mathrm{n}=240$ & $\mathrm{n}=80$ & $\mathrm{n}=80$ & $\mathrm{n}=80$ & \\
Age $($ years $) \pm$ SD & $64.12 \pm 12.94$ & $65.78 \pm 10.98$ & $64.18 \pm 15.21$ & $62.39 \pm 12.31$ & $\mathrm{P}=0.4190$ \\
Sex - male $(\mathrm{n} / \%)$ & $157(65.4 \%)$ & $49(61.25 \%)$ & $51(63.75 \%)$ & $57(71.25 \%)$ & $\mathrm{P}=0.3678$ \\
BMI $\left(\mathrm{kg} / \mathrm{cm}^{2}\right) \pm \mathrm{SD}$ & $25.92 \pm 6.845$ & $25.26 \pm 4.4$ & $24.60 \pm 4.5$ & $26.88 \pm 10.18$ & $\mathrm{P}=0.9679$ \\
SOFA \pm SD & $7.238 \pm 3.85$ & $4.57 \pm 1.43$ & $7.38 \pm 2.7$ & $9.74 \pm 4.72$ & $\mathrm{P}<0.0001$ \\
\hline
\end{tabular}


Table II. Groups of patients included in the study.

\begin{tabular}{|c|c|c|c|}
\hline \multicolumn{4}{|c|}{ Group A. Surgical - elective interventions $(n=80)$} \\
\hline Colon resections for colorectal cancer $(n=20)$ & \multicolumn{3}{|c|}{$\begin{array}{l}\text { Rectal cancer }(n=13) \\
\text { Colon cancer }(n=7)\end{array}$} \\
\hline Gastric resection surgery $(n=20)$ & \multicolumn{3}{|l|}{$\begin{array}{l}\text { Gastric cancer }(n=17) \\
\text { Pyloric stenosis }(n=3)\end{array}$} \\
\hline $\begin{array}{l}\text { Liver resections for primary and metastatic cancer } \\
(\mathrm{n}=20)\end{array}$ & \multicolumn{3}{|l|}{$\begin{array}{l}\text { Liver cancer }(n=11) \\
\text { Hepatic metastases }(n=9)\end{array}$} \\
\hline $\begin{array}{l}\text { Pancreatic resections and palliative interventions } \\
\text { regarding benign and malignant diseases of the pancreas } \\
(\mathrm{n}=10)\end{array}$ & \multicolumn{3}{|l|}{$\begin{array}{l}\text { Pancreatic cancer }(n=8) \\
\text { Pancreatic cysts }(n=2)\end{array}$} \\
\hline $\begin{array}{l}\text { Reconstructive vascular surgery with abdominal } \\
\text { approach }(n=10)\end{array}$ & \multicolumn{3}{|c|}{$\begin{array}{l}\text { Aortoiliac occlusive disease }(n=8) \\
\text { Abdominal aorta aneurysm }(n=2)\end{array}$} \\
\hline \multicolumn{4}{|c|}{ Group B. Surgical - emergency interventions $(\mathrm{n}=\mathbf{8 0})$} \\
\hline Acute intestinal obstruction $(\mathrm{n}=35)$ & \multicolumn{3}{|c|}{$\begin{array}{l}\text { Obstructive ileus }(\mathrm{n}=18) \\
\text { Strangulation ileus }(\mathrm{n}=10) \\
\text { Adhesive ileus }(\mathrm{n}=7)\end{array}$} \\
\hline $\begin{array}{l}\text { Mechanical jaundice from benign and malignant } \\
\text { diseases }(n=10)\end{array}$ & \multicolumn{3}{|c|}{$\begin{array}{l}\text { Malignant diseases }(n=12) \\
\text { Gull bladder calculosis }(n=3)\end{array}$} \\
\hline Secondary diffuse peritonitis $(\mathrm{n}=25)$ & $\begin{array}{l}\text { Colon perforations }(\mathrm{n}=1 \\
\text { Perforations of stomach } \\
\text { Small intestine perforat } \\
\text { Peritonitis of genital ori } \\
\text { Peritonitis of appendicu }\end{array}$ & $\begin{array}{l}\text { uodenal ul } \\
=3) \\
=2) \\
\text { gin }(n=2)\end{array}$ & \\
\hline \multicolumn{4}{|l|}{ Acute pancreatitis $(n=10)$} \\
\hline \multicolumn{4}{|c|}{ Group C. Medical $(n=80)$} \\
\hline $\begin{array}{l}\text { Respiratory failure } \\
(\mathrm{n}=40)\end{array}$ & $\begin{array}{l}\text { Bacterial pneumonia (n } \\
\text { COPD with infection ar } \\
\text { Marseilles fever ( } \mathrm{n}=3 \text { ) } \\
\text { Influenza with respirato } \\
\text { Myasthenia gravis ( } \mathrm{n}=2 \\
\text { Guillain-Barré syndrom } \\
\text { Myotonic dystrophy -S }\end{array}$ & $\begin{array}{l}\text { cerbation }( \\
(n=4) \\
(n=1)\end{array}$ & \\
\hline $\begin{array}{l}\text { Cardiac failure } \\
(\mathrm{n}=20)\end{array}$ & \multicolumn{3}{|c|}{$\begin{array}{l}\text { Left ventricular insufficiency }(n=14) \\
\text { Congestive cardiac insufficiency }(n=3) \\
\text { Acute myocardial infarction }(n=3)\end{array}$} \\
\hline $\begin{array}{l}\text { Liver failure } \\
(\mathrm{n}=10)\end{array}$ & \multicolumn{3}{|c|}{$\begin{array}{l}\text { Acute hepatitis B with hepatic coma }(n=4) \\
\text { Alcohol cirrhosis of the liver }(n=6)\end{array}$} \\
\hline $\begin{array}{l}\text { Coma } \\
(\mathrm{n}=10)\end{array}$ & \multicolumn{3}{|c|}{$\begin{array}{l}\text { Hemorrhagic cerebral infarction }(n=3) \\
\text { Ischemic cerebral infarction }(n=2) \\
\text { Other causes of coma }(n=5)\end{array}$} \\
\hline & Group A & Group B & Group C \\
\hline Number of patients (n) & 80 & 80 & 80 \\
\hline Minimum & 4.000 & 3.667 & 4.000 \\
\hline $25 \%$ Percentile & 6.333 & 7.083 & 8.000 \\
\hline Median & 7.500 & 10.00 & 10.00 \\
\hline $75 \%$ Percentile & 9.250 & 13.33 & 13.33 \\
\hline Maximum & 16.33 & 21.33 & 32.33 \\
\hline Average arithmetic value & 7.987 & 10.54 & 10.85 \\
\hline Standard deviation (SD) & 2.658 & 4.155 & 4.285 \\
\hline Standard error (SE) & 0.2972 & 0.4646 & 0.4791 \\
\hline Confidence interval of the lower $95 \%$ & 7.396 & 9.615 & 9.898 \\
\hline Confidence interval of the upper $95 \%$ & 8.579 & 11.46 & 11.81 \\
\hline \multicolumn{4}{|l|}{ Test for normal distribution of D'Agostino \& Pearson } \\
\hline K2 & 15.13 & 5.074 & 49.02 \\
\hline$P$ & 0.0005 & 0.0791 & $<0.0001$ \\
\hline Coefficient of variation $(\mathrm{V} \%)$ & $33.28 \%$ & $39.42 \%$ & $39.49 \%$ \\
\hline
\end{tabular}


Table IV. Frequency of incidence and severity of IAH in the study population.

\begin{tabular}{lllll}
\hline IAH & First $24 \mathrm{~h}$. & Second $24 \mathrm{~h}$. & Third 24 h. & Total of 72 h. \\
\hline Normal tension & $145(60.40 \%)$ & $141(58.75 \%)$ & $160(66.66 \%)$ & $161(67.08 \%)$ \\
Grade I & $66(27.50 \%)$ & $63(26.25 \%)$ & $56(23.33 \%)$ & $54(22.5 \%)$ \\
Grade II & $24(10 \%)$ & $30(12.50 \%)$ & $22(9.16 \%)$ & $21(8.75 \%)$ \\
Grade III & $4(1.66 \%)$ & $5(2.08 \%)$ & $5(2.08 \%)$ & $3(1.25 \%)$ \\
Grade IV & $1(0.41 \%)$ & $1(0.41 \%)$ & $1(0.41 \%)$ & $1(0.42 \%)$ \\
Total with IAH & $95(39.58 \%)$ & $99(41.25 \%)$ & $84(35 \%)$ & $79(32,91 \%)$ \\
\hline
\end{tabular}

Table V. Distribution of the IAH in the studied population for each group.

\begin{tabular}{llll}
\hline IAH & Group A $(\mathrm{n}=80)$ & Group B $(\mathrm{n}=80)$ & Group C $(\mathrm{n}=80)$ \\
\hline Normal tension & $70(87.5 \%)$ & $45(56.25 \%)$ & $46(57.5 \%)$ \\
Grade I & $8(10 \%)$ & $22(27.5 \%)$ & $24(30 \%)$ \\
Grade II & $2(2.5 \%)$ & $11(13.75 \%)$ & $8(10 \%)$ \\
Grade III & 0 & $2(2.5 \%)$ & $1(1.25 \%)$ \\
Grade IV & 0 & 0 & $1(1.25 \%)$ \\
Total with IAH & $10(12.5 \%)$ & $35(43.75 \%)$ & $34(42.5 \%)$ \\
\hline
\end{tabular}

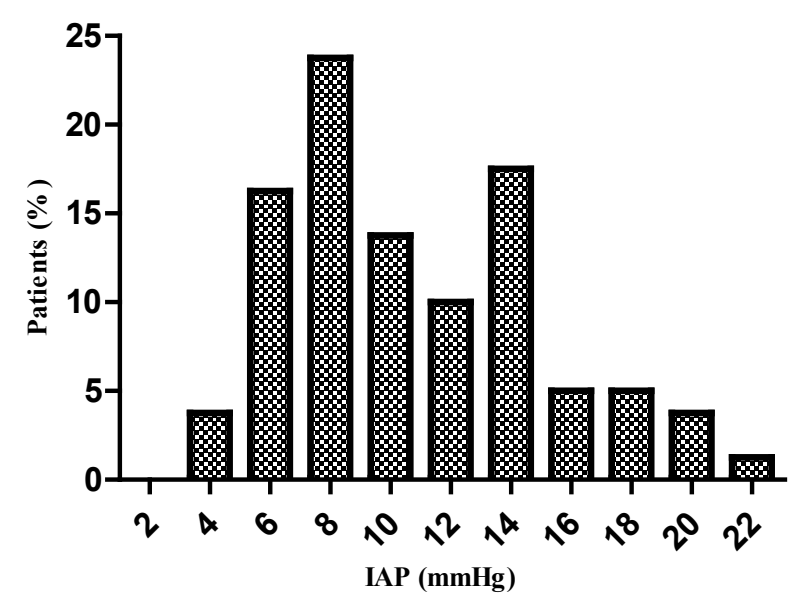

Figure 4. Incidence of IAH in Group B - emergency postoperative patients.

The incidence rates and severity of IAH in each of the three studied groups for the given period of time $(72 \mathrm{~h}$.) are presented in Table V, and shown in Figs. 3, 4, 5.

Table VI presents the comparative analysis of the measured values in each of the three groups in the studied patients' population and shown as a plot in Figure 7. The non-parametrical analysis of Kruskal-Wallis shows a statistically significant difference between the average measured values of the IAH for 72 hours period in each of the three groups patients, and from Dunn's test it is obvious that there is a difference between the group with elective postoperative patients and the other two groups, and at the same time there is no significant difference between the

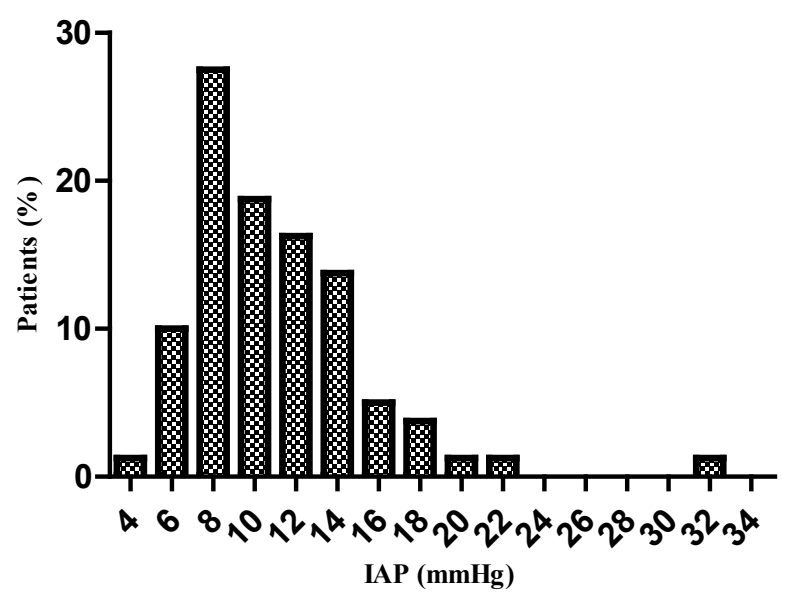

Figure 5. Incidence of IAH in Group $\mathrm{C}$ - medical patients.

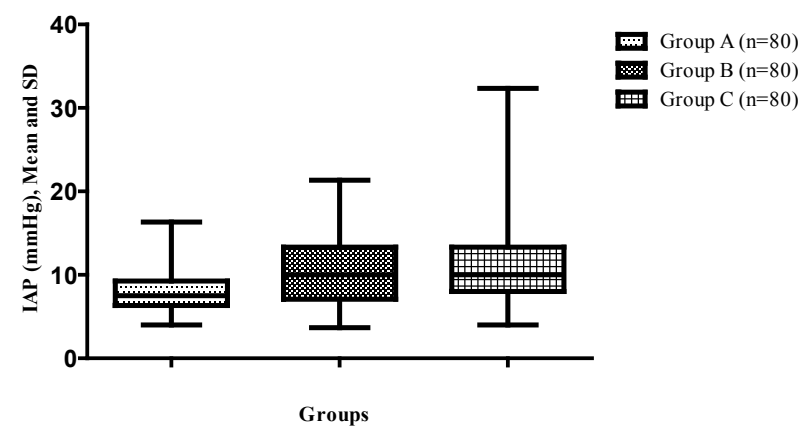

Figure 7. Box \& Whisker plot of IAP in all three groups.

Table VI. Kruskal-Wallis test and Dunn's multiple comparison test.

\begin{tabular}{lll}
\hline Test & Test value & Significance P \\
\hline Kruskal-Wallis test for all three groups & 26.51 & $\mathrm{P}<0.0001$ \\
Dunn's multiple comparison test & Difference & $\mathrm{P}<0.05 ?$ \\
Group A vs Group B & -44.75 & $\mathrm{P}<0.05$ \\
Group A vs Group C & -52.24 & $\mathrm{P}<0.05$ \\
Group B vs Group C & -7.494 & $\mathrm{P}>0.05$ \\
\hline
\end{tabular}


group of emergency postoperative patients and the group of medical critically ill patients when values of IAP are concerned.

\section{Discussion}

Malbrain et al. (2004) conducted a one-day multicenter prospective study which included 97 patients hospitalized in 13 mixed intensive care units (ICU) in 6 countries and established incidents of IAH in $50.5 \%$ of the patients, and ACS in $8.2 \%$ of them [6]. In a subsequent epidemiological research of 265 surgical and non-surgical patients entering the ICU, Malbrain et al. (2005) revealed that $32 \%$ had intra-abdominal pressure (IAP) $>12 \mathrm{mmHg}$, $4.2 \%$ had ACS on admission, and $12.9 \%$ developed abdominal compartment syndrome during their stay in the intensive care unit [7]. In patients undergoing surgery of the abdominal aorta, trauma, acute pancreatitis, peritonitis, ileus, burns, accidents of IAH vary between $20 \%$ and $64 \%$, and of ACS from $10 \%$ to $30 \%$. IAH/ACS mortality rates are from $30 \%$ to $80 \%$ (Smith, Cheatham 2011). After elective abdominal surgery frequency of incidents of IAH is between $12 \%$ and $29 \%$, and ACS cases are usually not registered (Scollay et al. 2009). In their clinical researches Sugrue et al. (1999) and Vidal et al. (2008) studied mixed populations of ICU patients (therapeutic and surgical), where they reported between $41 \%$ and $64 \%$ of IAH cases, and $23 \%$ of ACS respectively, with $60 \%$ mortality $[8,9]$. Reguiera et al. (2008) studied a mixed group of patients admitted to the ICU with septic shock and found out that $82 \%$ had IAH, and $40 \%$ of them had ACS [10]. Ejike et al. (2007) established that $17.6 \%$ of the patients on mechanical ventilation in the pediatric intensive care units had abdominal compartment syndrome, and moreover these children had a significantly higher mortality (33.3\%). Analyses show that the ACS is not only found in children with injuries but is also observed in critically ill children with different nosology, including sepsis, intestinal perforation, necrotizing eneterocolitis, meningitis, invaginations, gastroschisis [11].

Table VII shows most of the published results of IAH for studied population of patients in intensive care

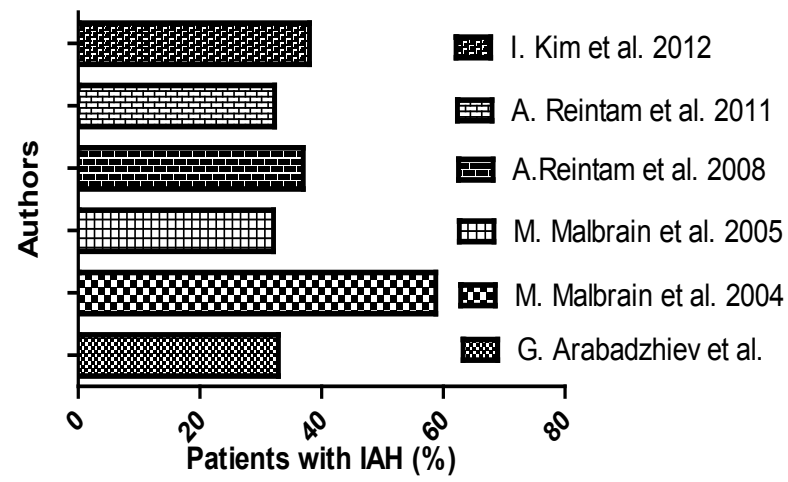

Figure 8. Comparison of incidence of intra-abdominal hypertension (\%) in mixed population of patients. units that were included in single center and multicenter studies. Table VIII shows the incidence of IAH in mixed population of patients in comparison to our results which are presented on Fig. 8 .

We examined the incidence and severity of intraabdominal hypertension in three groups of patients (elective and emergency surgery, and medical) in the intensive care unit for a period of 72 hours. It was established that $32.91 \%$ of all patients had intra-abdominal hypertension, $22.5 \%$ from which had grade I, $8.75 \%$ had grade II and $1.25 \%$ had grade III. The incidence of IAH in the group of patients that underwent elective surgery was $12.5 \%$, mainly grades I and II. Among the patients that underwent emergency surgery the IAH incidence was $43.75 \%$, and $2.5 \%$ of them had grade III hypertension. The incidence of IAH in the medical group was $42.5 \%$, with $2.5 \%$ having grades III and IV hypertension and $10 \%$ grade II. It was established that there was a significant difference in the values of IAP measured within the group of elective surgery and the other two groups. However, there was no significant difference between the therapeutic group and that emergency surgery group. Our results are comparable with the results of other single- and multi-center studies that examine the incidence and severity of IAH in mixed patients' population. There is no significant statistical difference between the incidence of IAH in the studied mix population group as it is according to the results other authors present after observing the same type of patients' group $(\mathrm{P}=0.4159)$.

After more than 100 years, the problems of intraabdominal hypertension described in the pioneer studies of the 18th and 19th century, were rediscovered after the publication of Irving Kron in 1984, who measured the intraabdominal pressure intravesically, and used it as a criteria for re-laparotomy in patients who underwent surgery for complicated aneurysms of the abdominal aorta. R. Fietsam (1989) is the first one to use the term abdominal compartment syndrome, referring to the cases of four patients that underwent surgery for aneurysms of the abdominal aorta, caused by massive interstitial and retroperitoneal edema, and not by intraperitoneal hemorrhage. The constantly increasing interest in intra-abdominal pressure, and all related to it changes in the clinical management of critically ill patients has led to an exponential growth in research work on this matter regarding both intra-abdominal hypertension and abdominal compartment syndrome in recent years. In the updated consensus guidelines for clinical practice from 2013, the World Society of the Abdominal Compartment Syndrome recommended measuring of the intra-abdominal pressure in all patients in intensive care which happen to be at risk of developing intra-abdominal hypertension.

Early recognition and diagnosis of IAH combined with appropriate therapeutic scheme led to a significant reduction in morbidity and mortality. Cheatham and Safcsak (2010) on studying 478 patients with ACS (post traumatic and underwent vascular surgery), who were 
Table VII. Incidence of the intra-abdominal hypertension and the abdominal compartment syndrome in single center and multicenter studies in different population of patients.

\begin{tabular}{|c|c|c|c|}
\hline Author & Patients' population & Number & Incidence of IAH and ACS \\
\hline $\begin{array}{l}\text { M. Sugrue (Australia) } \\
1999\end{array}$ & $\begin{array}{l}\text { Elective and emergency } \\
\text { surgery }\end{array}$ & $\mathrm{n}=263$ & $\begin{array}{l}\text { IAH } 46 \% \text { of the emergency patients } \\
\text { IAH } 29 \% \text { of the elective patients }\end{array}$ \\
\hline $\begin{array}{l}\text { E. Wolfgang } \\
\text { (Switzerland), } 2000\end{array}$ & $\begin{array}{l}\text { Posttraumatic with "Damage } \\
\text { control" laparotomy }\end{array}$ & $\mathrm{n}=311$ & ACS $5.5 \%$ \\
\hline $\begin{array}{l}\text { M. Malbrain (Belgium) } \\
\text { Multicentric study } \\
\text { In six countries - } 13 \\
\text { ICU, } 2004\end{array}$ & Mixed ICU & $\mathrm{n}=97$ & $\begin{array}{l}\text { IAH } 58.8 \% \\
\text { ACS } 8,2 \%\end{array}$ \\
\hline $\begin{array}{l}\text { M. Malbrain (Belgium) } \\
\text { Multicentre study } \\
\text { In six countries - } 14 \text { ICU, } \\
2005\end{array}$ & Mixed ICU & $\mathrm{n}=265$ & $\begin{array}{l}\text { IAH } 32.1 \% \\
\text { ACS } 4.2 \%\end{array}$ \\
\hline $\begin{array}{l}\text { P. Keskinen (Finland) } \\
2007\end{array}$ & Acute pancreatitis & $\mathrm{n}=37$ & $\begin{array}{l}\text { IAH } 84 \% \\
\text { ACS } 49 \% \\
\end{array}$ \\
\hline S. Busani (Italy) 2006 & Emergency surgery & $\mathrm{n}=22$ & $\begin{array}{l}\text { IAH } 63.6 \% \\
\text { ACS } 14,2 \%\end{array}$ \\
\hline H. Chen (China) 2008 & Acute pancreatitis & $\mathrm{n}=74$ & $\begin{array}{l}\text { IAH } 59 \% \\
\text { ACS } 27 \%\end{array}$ \\
\hline A. Basu (India) 2008 & Emergency surgery & $\mathrm{n}=78$ & IAH $41 \%$ \\
\hline M. Beltran (Chilie) 2008 & Ileus & $\mathrm{n}=81$ & $\begin{array}{l}\text { Pre-operative: IAH } 60 \% \text {; ACS } 19 \% \text {; Strangulation: } \\
\text { IAH } 88 \% \text {; ACS } 47 \% \text {; Incarceration: IAH } 43 \% \text { ACS } \\
0 \%\end{array}$ \\
\hline $\begin{array}{l}\text { A. Reintam (Estonia) } \\
2008\end{array}$ & Mixed ICU & $\mathrm{n}=257$ & $\begin{array}{l}\text { ИАХ } 37 \% \\
\text { Primary IAH } 23.3 \% \\
\text { Secondary IAH } 13.6 \%\end{array}$ \\
\hline $\begin{array}{l}\text { M. Vidal (Argentina) } \\
2008\end{array}$ & Mixed ICU & $\mathrm{n}=83$ & $\begin{array}{l}\text { IAH } 64 \% \\
\text { ACS } 23 \%\end{array}$ \\
\hline M. Saaiq (Pakistan) 2009 & $\begin{array}{l}\text { Elective and emergency } \\
\text { surgery }\end{array}$ & $\mathrm{n}=200$ & ACS $3 \%$ \\
\hline $\begin{array}{l}\text { Z. Dambrauskas } \\
\text { (Lithuania) } 2009\end{array}$ & Acute pancreatitis & $\mathrm{n}=44$ & $58 \%$ - IAH; $19.35 \%$ ACS \\
\hline J. Scollay (UK) 2009 & Elective surgery & $\mathrm{n}=42$ & IAH $12 \%$ \\
\hline S. Khan (India) 2010 & Emergency surgery & $\mathrm{n}=197$ & $\begin{array}{l}\text { Pre-operative: Surgical patients IAH } 83,65 \% \text {; } \\
\text { Posttraumatic patients IAH } 65.79 \%\end{array}$ \\
\hline $\begin{array}{l}\text { A. Reintam (Estonia) } \\
2011\end{array}$ & Mixed with CMV & $\mathrm{n}=563$ & $\begin{array}{l}\text { IAH } 32,3 \% \\
\text { ACS } 1.1 \%\end{array}$ \\
\hline $\begin{array}{l}\text { P. Santa-Teresa (Spain) } \\
2012\end{array}$ & Mixed with risk of IAH & $\mathrm{n}=87$ & IAH $67.8 \%$ \\
\hline I. Kim (Australia) 2012 & Mixed ICU & $\mathrm{n}=100$ & IAH $38 \%$ \\
\hline
\end{tabular}

Table VIII. Incidence of intra-abdominal hypertension (\%) in mixed population of patients in intensive care units according to different authors.

\begin{tabular}{llllllll}
\hline $\begin{array}{l}\text { Malbrain } \\
2004\end{array}$ & $\begin{array}{l}\text { Malbrain et al. } \\
2005\end{array}$ & $\begin{array}{l}\text { Reintam et al. } \\
2008\end{array}$ & $\begin{array}{l}\text { Reintam et al. } \\
2011\end{array}$ & $\begin{array}{l}\text { Kim et al. } \\
2012\end{array}$ & Arabadzhiev et al. & P \\
\hline $58.8 \%$ & $32.1 \%$ & $37 \%$ & $32.3 \%$ & $38 \%$ & $32.91 \%$ & 0.4159 \\
\hline
\end{tabular}

treated according to the guidelines of the World Society of the Abdominal Compartment Syndrome, reported a significant increase from $50 \%$ to $72 \%$ in survival, primary fascial closure of $59 \%$ to $81 \%$ and reduced hospital costs $[12,13]$.

Before there are any indications for surgical decompression, we should optimize the less invasive treatment options. Most of the recommended therapeutic methods are based on five different main mechanisms: improving the compliance of the abdominal wall; evacuation of the intraluminal content; evacuation of abdominal fluid collections; correction of positive fluid balance and treatment of increased capillary permeability; specific treatment. Non-operative strategies play an important role in the clinical approach of patients with intra-abdominal hypertension and abdominal compartment syndrome. Of course, when the ACS is refractory to all kinds of therapeutic approaches, decompressive laparotomy 
should not be delayed. Optimizing the fluid balance, the application of renal substitute therapy, the study on the effect of thoracic epidural analgesia and transverse abdominal block, are methods that have the potential to serve as tools for reduction of IAP and to improve organ function, but are still a subject of examination.

\section{Conclusion}

The clinical examination as a method itself is inaccurate for determining the presence of IAH. A standardized measurement of the intra-abdominal pressure is fundamental for the establishment of intra-abdominal hypertension and abdominal compartment syndrome. The identification of patients at risk of developing IAP/ACS by screening measures of IAP is important and helps undertake effective preventive therapeutic actions. The IAH is an important clinical problem in patients in the intensive care units. Increased intra-abdominal pressure has a harmful effect upon intra- and extra-abdominal organs and systems. The IAH not only causes dysfunction of many organs and systems, but also increases the mortality of critically ill patients. The mortality rate (from $30 \%$ to $80 \%$ ) associated with ACS dropped by more than $1 / 3$ in the last decade with the introduction of regular IAP monitoring and early recognition of IAH by applying appropriate therapeutic methods.

\section{References}

1. Kimball EJ, Rollins MD, Mone MC, Hansen HJ, Baraghoshi GK, Johnston C, et al. Survey of intensive care physicians on the recognition and management of intra-abdominal hypertension and abdominal compartment syndrome. Crit Care Med. 2006;34(9):2340-2348.

2. Ravishankar N, Hunter J. Measurement of intra-abdominal pressure in intensive care units in the United Kingdom: a national postal questionnaire study. Br J Anaesth. 2005;94(6):763-766.

3. Nagappan R, Ernest D, Whitfield A. Recognition and management of intra-abdominal hypertension and abdominal compartment syndrome. Crit Care Resusc. 2005;7:298-302.

4. Costa S, Gomes A, Graça S, Ferreira A, Fernandes G, Esteves J, et al. Abdominal compartment syndrome: survey on the awareness of Portuguese general surgeons. Acta Med Port. 2011;24 Suppl 2:131-136.

5. Kaussen T, Otto J, Steinau G, Höer J, Srinivasan PK, Schachtrupp A. Recognition and management of abdominal compartment syndrome among German anesthetists and surgeons: a national survey. Ann Intensive Care. 2012;2(Suppl 1):S7.

6. Malbrain ML. Is it wise not to think about intraabdominal hypertension in the ICU? Curr Opin Crit Care. 2004;10(2):132145.

7. Malbrain ML, Chiumello D, Pelosi P, Bihari D, Innes R, Ranieri
VM, et al. Incidence and prognosis of intraabdominal hypertension in a mixed population of critically ill patients: a multiple-center epidemiological study. Crit Care Med. 2005;33(2):315-322.

8. Scollay JM, de Beaux I, Parks RW. Prospective study of intraabdominal pressure following major elective abdominal surgery. World J Surg. 2009;33(11):2372-2377.

9. Vidal MG, Ruiz Weisser J, Gonzalez F, Toro MA, Loudet $\mathrm{C}$, Balasini $\mathrm{C}$, et al. Incidence and clinical effects of intraabdominal hypertension in critically ill patients. Crit Care Med. 2008;36(6):1823-1831.

10. Regueira T, Bruhn A, Hasbun P, Aguirre M, Romero C, Llanos $\mathrm{O}$, et al. Intra-abdominal hypertension: incidence and association with organ dysfunction during early septic shock. J Crit Care. 2008;23(4):461-467.

11. Ejike JC, Humbert S, Bahjri K, Mathur M. Outcomes of children with abdominal compartment syndrome. Acta Clin Belg Suppl. 2007;(1):141-148.

12. Cheatham ML, Safcsak K. Is the evolving management of intra-abdominal hypertension and abdominal compartment syndrome improving survival? Crit Care Med. 2010;38(2):402407.

13. Cheatham ML. Nonoperative management of intraabdominal hypertension and abdominal compartment syndrome. World $\mathrm{J}$ Surg. 2009;33(6):1116-1122.

14. Reintam A, Parm P, Kitus R, Kern H, Starkopf J. Primary and secondary intra-abdominal hypertension--different impact on ICU outcome. Intensive Care Med. 2008;34(9):1624-1631.

15. Reintam Blaser A, Parm P, Kitus R, Starkopf J. Intra-abdominal hypertension and gastrointestinal symptoms in mechanically ventilated patients. Crit Care Res Pract. 2011;2011:982507.

16. Santa-Teresa P, Muñoz J, Montero I, Zurita M, Tomey M, Alvarez-Sala L, et al. Incidence and prognosis of intra-abdominal hypertension in critically ill medical patients: a prospective epidemiological study. Ann Intensive Care. 2012;2(Suppl 1):S3.

17. Kim IB, Prowle J, Baldwin I, Bellomo R. Incidence, risk factors and outcome associations of intra-abdominal hypertension in critically ill patients. Anaesth Intensive Care. 2012;40(1):79-89. 18. Khan S, Verma AK, Ahmad SM, Ahmad R. Analyzing intra-abdominal pressures and outcomes in patients undergoing emergency laparotomy. J Emerg Trauma Shock. 2010;3(4):318325 .

19. Dambrauskas Z, Parseliunas A, Gulbinas A, Pundzius J, Barauskas G. Early recognition of abdominal compartment syndrome in patients with acute pancreatitis. World J Gastroenterol. 2009;15(6):717-721.

20. Saaiq M. Abdominal compartment syndrome among critically ill surgical and traumatised patients: experience at Pims, Islamabad. J Ayub Med Coll Abbottabad. 2009;21(2):151-155.

21. Busani S, Soccorsi MC, Poma C, Girardis M. Intra-abdominal hypertension in nonelective surgery: a preliminary report. Transplant Proc. 2006;38(3):836-837.

22. Keskinen P, Leppaniemi A, Pettila V, Piilonen A, Kemppainen $\mathrm{E}$, Hynninen M. Intra-abdominal pressure in severe acute pancreatitis. World J Emerg Surg. 2007;2:2. 